\title{
Pre-Interview Activities and the Art of Hermeneusis
}

\author{
Vicki Macris \\ University of Alberta, Canada
}

\begin{abstract}
In this paper, I provide an account of my exploratory interview with a grade 9 student, Enzo (pseudonym), and his experiences of being at school before and after immigrating to Edmonton, Alberta, Canada. Key aspects of the research process are highlighted, whereby pre-interview activities are used to visualize interpretive inquiry as a formal research process. By identifying key findings from my work, I explore how the dynamics of interpretation constitute our very mode of being. I draw on the insights of [1] to suggest that to interpret a text is to come to understand the possibilities of being that are revealed. In order to better understand the lived experiences of immigrant students and their transitions into public school settings, I will elucidate how I have employed interpretive (holistic hermeneutic) modes of inquiry as a formal qualitative research method to attend to modes of being.
\end{abstract}

\section{Introduction}

In this paper, I provide an account of one exploratory interview with a grade 9 immigrant student, Enzo (pseudonym), and his experiences of being at school before and after immigrating to Edmonton, Alberta, Canada. Before providing details of the interview itself, I discuss some of the guiding principles of hermeneutics and exegesis by which interpretation and interpretive inquiry as a hermeneutic practice are possible.

I begin by highlighting key aspects of the research process, whereby pre-interview activities are used to visualize interpretive inquiry as a formal research process, followed by identifying key findings from my work by exploring how the dynamics of interpretation constitute our very mode of being. I draw on the insights of [1], [2], [3] and others, to suggest that to interpret a text is to come to understand the possibilities of being that are revealed.

In educational situations, according to Lincoln and Guba [11], different interpretations are likely to be meaningful for different realities. The validity of interpretations depends heavily on local particulars and on the values of the investigator and the individuals in the setting. Pre-interview activities contribute to learning about a participant's life, at a deeper level, that could help a researcher to better understand the views the participant expressed about the research topic, while each situation is understood as idiosyncratic and unique. Interpretive inquiry allows the researcher to "make the path by walking it" [4] (pp. 50); it enables research to be humanised. The goals of interpretive inquiry, or research guided by key ideas from hermeneutics are to clarify wholepart relationships and to inform more adequate interpretation that aims for holistic understanding, rather than reducing what is learned to pre-existing categories, and appreciating that the language and history of one's community both enable and limit interpretation ([2]; [5], as cited in [6]). According to [7], there is a wide held assumption that educational research is not "scientific" enough, in the empiricist and/or positivist sense. Interpretivists, however, see research as an "eminently practical and moral activity that shares much in common with, or is continuous with, other forms of inquiry, such as those practiced by journalists, novelists, painters, poets, and ordinary people in their day-to-day lives" (Smith, p. 1). Hermeneutics is about creating meaning, not simply reporting it. Interpretation is the way human beings are, while experience itself is formed through interpretation of the world. Therefore, interpretation and understanding are creative acts, not just technical functions [3]. [8] calls for the need to look at inquiry from the two basic dimensions of science and art and in that process re-describe of what we ourselves are like and what unfamiliar people and voices are like Barone. It is, thus, the inherently creative character of interpretation, of the interpreter who works holistically in an effort to discern the intent or meaning behind the other's expression [1].

Hermeneutic philosophy informs the conduct of my research through a phenomenological investigation that aims to grasp the lived experiences immigrant students, i.e., how these students make sense of and engage with their schooling environments, their interactions with teachers, other immigrant or indigenous students and learning processes in the classroom. This study has evolved out of my belief (and personal experience) that immigrant students have been and continue to be marginalized, excluded, or forgotten in policy implementation. My attempt to understand who I am and what I do as an inquirer, as a researcher, involves "coming to terms with hermeneutics" [7] insofar as understanding is not merely the process of seeing clearly the ways in which self-understanding or subjectivity emerge from a set of particular conditions - but to see how my own identity opens 
out onto the horizon of other identities [5]. Therefore, the purpose of employing hermeneutics through interpretive inquiry as a formal research process that necessarily arises out of interactions that work outward and back from self to event and event to self [1], is not to translate my subjectivity out of the picture, but to take it up with a new sense of responsibility. To understand, not in the sense of argument or stating my claim, but rather, in a dialectical sense that "requires that one does not try to argue the other person down but that one really considers the weight of the other's opinion."

In attempting to acquire an holistic understanding of the participants' experiences, I used open-ended questions about both the topic and the participants' lives in general; that is, I asked the participant to complete pre-interview activities such as (a choice) drawings or diagrams about the topic or their lives in general. I framed the guiding data collection question as:

\section{"How does the participant experience [topic of interest]" [6]?}

I subsequently revised the research questions or changed their ideas about how to do the interviews based upon what transpired in these interviews. The value of research on classroom issues or practices depends upon the use of pertinent research questions and productive approaches to any interviews undertaken. I thought it necessary, therefore, to "test the water" through an initial exploratory interview, before undertaking any large-scale study and data collection that will contribute to my doctoral work. In what follows, I report on a first interview with a "field test" participant and explain how what I have learned prompted me to re-frame or refocus either my research questions or interview plans. This process has enabled me to acquire a more holistic understanding of my participant's experiences and alerted me to important whole-part relationships. Furthermore, the understandings and insights acquired from this exploratory interview have prompted me to re-focus my research questions and/or alter my ideas about interview approaches [6].

According to Guba and Lincoln, qualitative research conducted in the constructivist/interpretive paradigm is necessarily hermeneutical. My study is informed by key themes drawn from hermeneutics and the importance of clarifying whole-part relationships to inform more adequate interpretation, aiming for holistic understanding rather than reducing what is learned to pre-existing categories, and appreciating that the language and history of one's community both enable and limit interpretation [2], [5].

Hermeneutics is "the art of understanding;" a way of coming to terms with the foreign and unfamiliar. Hermeneutics precisely holds a place for the possibility of renewal, for the rebirth of the spirit, for new life, as it attends to the ruptures and irregularities in existence; in being. And while hermeneutics is certainly not a "method" of determining truth, it is a way of understanding the conditions that make truth possible; it is a way through which qualitative researchers, such as myself, come to understand others through interpretation in light of an already existing web of background meanings and/or theories [2].

Key metaphors from hermeneutics, as indicated in [1], include the hermeneutic circle and understanding interpretive inquiry as a spiral, with each loop in the spiral representing a separate data collection or analysis activity. Each loop in the spiral can also be understood as a distinct hermeneutic circle with its own forward projective arc and backward evaluative arc. In a forward projective arc, the researcher makes sense of what is encountered by drawing from previous experience or expectations-forestructure and pre-understandings (prejudices) in hermeneutic terms. In the backward arc this first interpretation is evaluated by re-examining the data for contradictions, gaps, or material not adequately explained by the first interpretation. The goal in the backward arc is to develop the most adequate interpretation that best addresses all that was found. What one learns, notices, or recognizes as a new question in the backward arc gives direction or purpose to the next loop or research activity [1].

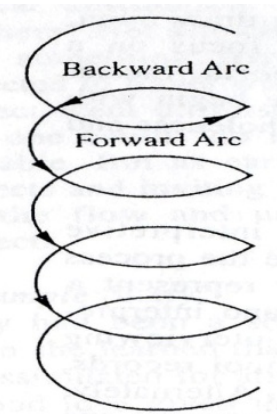

\section{Figure 1. Interpretive Inquiry as an Unfolding Spiral ${ }^{1}$}

Specifically:

- The loops represent the consecutive efforts to reinterpret text or data.

- Each loop represents a different attempt to get closer to what one hopes to understand.

- $\quad$ Each loop may be a separate question that gives us information and a sense of direction as we then reframe the question for the next loop.

\footnotetext{
${ }^{1}$ Taken from Ellis, J. (1998). Interpretive Inquiry as a Formal Research Process. In S.R. Steinberg and J. L. Kincheloe (Eds.), Students as researchers: creating classrooms that matter (pp.49-62). UK: Falmer Press.
} 
- What is learned may effect change; the direction of the study, possibly a dramatic "uncovering" through other parts of the spiral.

- Interpretive inquiry is an unfolding of the spiral. While it may not lead to solutions, it enables the researcher to understand the problem or question differently so as to reframe the question [1].

This spiral of understanding and interpretation describes the process of creativity and the discovery of new knowledge. The hermeneutical process "avers the transformative nature of engaging with an experience which claims and compels the researcher to know and appreciate the experience studied in increasingly subtle and yet expanded ways as the inquiry continues. Often the researcher is greatly changed and transformed by this iterative hermeneutical endeavour" [9].

If the first research activity in a study is conducted in the right way it has the potential to change the direction of the study quite dramatically [1]. Scholars in hermeneutics have clarified that beginning the research or entering the hermeneutic circle in the right way requires: concerned engagement; humility; openness; a capacity for reciprocity and interactive, dialogic interviews; and availability to negotiation of meaning [10], [2], [7], [5]. The particular interview processes I have undertaken, was intended to enhance the likelihood of entering the circle in the right way (as cited in [6]).

Regardless of the research questions, I framed a main question to guide my data collection or the interview in the following format: "How does the participant experience.... the topic of interest?" Taking this broad view or goal for the interviews allows the researcher to learn about the participants' experience holistically. All that was learned could be "mined" for how it related to the initial research question [6].

Another strategy was to invite participants to complete a pre-interview activity such a drawing, diagram or list that was related to either the research topic or the participant's life more generally [4].

Examples are:

1. Draw a picture of a good day and a not-so-good day with the event/experience of

2. interest.

3. Make a diagram to show the support systems in your life or work.

4. Make a timeline showing critical events in your experience of the topic.

The participant in my study was offered several pre-interview activities and then asked to choose and complete one to bring to the interview.

The third strategy was to prepare open-ended interview questions pertaining to the research

topic or the participant's life in general. Examples are:

1. What has surprised you about this experience?
2. What has been most difficult about this experience?

3. What has been most beneficial about this experience?

4. Over time, how has this experience changed or stayed the same?

5. If you only had to go to school/work three days a week, how would you spend the extra time?

The two strategies of using pre-interview activities and open-ended questions are intended to support participants in recalling and sharing stories related to the research topic or their lives more generally. Participants can only communicate their experiences through narratives [11]. If the interview provides a facilitative and inviting space for participants to share many stories, researchers can learn what a topic is about for participants-what is salient or meaningful in their experience of the research topic; that is, what is its significance-and can consider a number of whole-part relationships in interpretation.

\section{My study}

With an interview that used a pre-interview activity and some prepared open-ended questions, I hoped to learn something about what it had been like for Enzo, a student who immigrated to Canada to attend school. In this study, I treated this interview as a "first interview" knowing that in my actual study there will be additional interviews to follow-up on important sub-topics identified in the first interview.

Education encourages detailed attention to the care of students as human beings and grounds its practice in a holistic belief system that nurses care for the mind, body and spirit of the child. A holistic approach and avoidance of reductionism are, therefore, vital for educational research - especially in research that involves children.

In my research program my key questions are concerned with how well school level policies meet the needs of immigrant students and improve immigrant education; if they are, in fact, implemented, enacted and supported. The crux of doctoral research is to gain deeper insight into the life, world and experiences of immigrant students and to explore the ways in which school level policies meet (or not) the needs of immigrant students and improve immigrant education. Immigrant students experience marginalization, exclusion, isolation and invisibility in dominant culture-normed schooling environments; as such, improving the educational experience of immigrant students should be a policy priority for immigrant receiving countries.

The question guiding data collection in the interview was:

How has Enzo experienced schooling after immigrating to Canada? 
For my initial exploration of interviewing a student who had immigrated to Canada, I worked with a 14 year old boy whom I will call, Enzo. Enzo was one of my grade 9 students and since I interviewed him early on in the school year, our relationship had not been well established, so I knew very little about Enzo's life. Because Enzo had been in Canada for five years, I expected that he would be able to recall, reflect upon, and articulate his experiences of school in Canada. Prior to the interview I offered Enzo seven pre-interview activities from which to choose one.

Pre-interview Activities:

1) Make a schedule of your day or week before you came to Edmonton and show how your schedule has changed or not changed now that you are in Edmonton.

2) Draw two pictures to represent what you anticipated your response would be to coming to a new school in Edmonton and what your actual response was. (Alternatively, this could be to draw how your life was before and after coming to Edmonton).

3) Draw two pictures to show what your life was like before you came to your new school in Edmonton and what your life is like now in your school in Edmonton.

4) Draw a diagram and label it to show the happy times/events in your new school.

The one Enzo selected was: "Draw two pictures to show what your schooling (your life at school) was like before you came to your new school in Edmonton and what your life is like now in your school in Edmonton."

After critically reflecting on the relations of power between a teacher and student for some time, I became acutely aware, initially, of the two sets of power dynamics that existed between Enzo, who was my student, and myself: that of teacher and researcher and how these power dynamics have impacted (altered or affected) my research study.

As I became aware of the power dynamics in place, I almost "expected" that Enzo would praise his schooling experiences in Canada; I expected that he would speak very positively of his learning experience in Canadian schools, about his teachers and classmates, about life in Canada. I felt that, perhaps, Enzo did not want to come across as being ungrateful for the opportunity to come to Canada. He wanted to be liked. He compared his schooling in Canada to his "circus" (his words) schooling in Iraq, where children are "allowed to finish their smoke outside the classroom;" where "teachers didn't care about education. What education?" He stated. Enzo has been to both public and private schools; his mother had to pay so that he "could learn something”.

As Enzo and I sat together around his drawings he began by telling me much about his past.
He talked about how his family had been driven out of his birth country, Kurdistan. He explained that "no one here in Canada knows what Kurdistan is, so I tell them I'm from Iraq." He talked about being "Kurdish and having no country" and how he feels a sense of belonging in Canada because "people are nice, they care...they are like me.”

In his own words:

VM - Tell me about your relationships between you and other immigrant students and other students ("Canadian" students) at your school.

E - I don't have a country and when they ask me and I tell them, they don't know it; they don't know Kurdistan, so I say I'm from Iraq; people know Iraq. I have no friends from there (Kurdistan), but I hang out mostly with other immigrant students because I have a lot more common things with them...

Enzo was quite surprised that I knew where Kurdistan was and how I was aware of the Kurdish peoples' struggles. Allowing Enzo the space and time to tell me his story - which revealed so much more that I ever imagined - made me realize that "personal meaning is not always immediately available to consciousness, ready to be expressed briefly and quickly" [12].

Enzo's drawings and related stories ignited my own comments and further questions, thereby supporting an intense dialogue between us. With the drawings as the centerpiece for starting our interview, Enzo spoke confidently and enthusiastically, taking the lead as he told me much more about his drawings. He described the tumultuous conditions and his (chaotic) schooling experiences and "escape" from Iraq through mountains and valleys in the context of bomb explosions and constant gunfire. His younger brother was killed in one of the bombings. He described his arrival to Canada as finding "the pot of gold at the end of the rainbow."

Enzo's drawings elicited several questions, primarily because the images he chose to create had little to do with schooling and much more to do with how he understood and contextualized his life in Canada (his current country) and (compared to) Iraq (the last, of several countries he and his family fled). From the drawings, I was able to construct subsequent interview questions.

While Enzo's drawings allowed, or rather, stimulated the emergence of detailed dialogue, there were noticeable shifts, turns and twists in Enzo's story that were not necessarily (nor immediately) providing me with the answers I imagined I needed.

\section{Interviewing Children}

I remembered that I must not only be persistent, but patient; that children and youth have their own sense-making and ways of proceeding [4]. Thus it was important to create conditions that enabled Enzo 
to recall and consider past experiences and express, or articulate their significance from his perspective. The pre-interview drawing and its use at the beginning of the interview helped to make that possible.

My interview experience with Enzo has not changed my research interest or purposes. It has, however, changed the way I will think about developing my interview questions for other students and participants.

\section{References}

[1] Ellis, J. (1998). "Interpretive Inquiry as a Formal Research Process”, in S.R. Steinberg and J. L. Kincheloe (Eds.), Students as researchers: creating classrooms that matter (pp.49-62). UK: Falmer Press.

[2] Smith, D. G. (1991). "Hermeneutic inquiry: The hermeneutic imagination and the pedagogic text”, in E. C. Short (Ed.), Forms of Curriculum Inquiry (pp.187-209). Albany, NY: SUNY.

[3] Hultgren, F. H. (1994). "Interpretive inquiry as a hermeneutic practice", Journal of Family and Consumer Sciences Education, 12 (1), pp. 11-25.

[4] Ellis, J. (2006). "Researching Children's Experience Hermeneutically and Holistically", The Alberta Journal of Educational Research, Vol. 52, No. 3, Fall 2006, pp. 111126.

[5] Smith, D.G. (2002). "Hermeneutic scholar", in M. P. Woolfe and C. R. Pryor (Eds.), The mission of the scholar: research and practice $-A$ tribute to Nelson Haggerson (pp. 183-200). New York: Peter Lang.

[6] Ellis, Janjic-Watrich, Macris and Marynowski (2011), "Using Exploratory Interviews to Re-frame Planned Research on Classroom Issues", Journal of Educational Practices, pp. 11-18.

[7] Smith, J. K. (1993), "Hermeneutics and qualitative inquiry", in D. J. Flinders and G. E. Mills (Eds.), Theory and concepts in qualitative research: Perspectives from the field, pp. 183-200, New York: Teacher’s College Press.

[8] Barone, T. E. (1990). "Rethinking the meaning of rigor: Toward a literary tradition of educational inquiry", The Annual Meeting of the American Education Research Association, Boston, MA.

[9] Anderson, R. (2000). "Intuitive inquiry: Interpreting objective and subjective data", ReVision: A Journal of Consciousness and Transformation, 22(4), pp. 31-39.

[10] Packer, M. J., and Addison, R. B. (1989). "Evaluating an interpretive account", in M. J. Packer and R. B. Addison (Eds.), Entering the Circle: Hermeneutic Investigation in Psychology (pp. 275-292). Albany, NY: SUNY.

[11] Lincoln, Y. S., \& Guba, E. G. (1985). Naturalistic inquiry. Beverly Hills, CA: Sage Publications, Inc.
[12] Carr, D. (1986). "The self and the coherence of life", in D. Carr, Time, narrative, and history, pp. 73-99, Bloomington, IN: Indiana University Press.

[13] Stinson, S.W., Blumenfield-Jones, D., and Van Dyke, J. (1990). "Voices of young women dance students: An interpretive study of meaning in dance", Dance Research Journal, 22, pp. 13-22. 